JURNAL ILMU PEMERINTAHAN:

Kajian IlmuPemerintahan dan Politik Daerah

Volume 4- Nomor 1, April 2019, (HIm 29-38)

Available online at: http://e-journal.upstegal.ac.id/index.php/jip

Doi: http://dx.doi.org/10.24905/jip.v4i1.1072

\title{
Partisipasi Politik Masyarakat dalam Pemilihan Kepala Daerah Kota Baubau Tahun 2018
}

\author{
L.M. Azhar Sa'ban 1), Anwar Sadat 2), Nastia ${ }^{3)}$ \\ 1,2,3 Program Studi Ilmu Pemerintahan, Fakultas Ilmu Sosial Dan Ilmu Politik Universitas \\ Muhammadiyah Buton. Jalan Betoambari No.36, Kota BauBau, Sulawesi Tenggara, 93717 \\ Indonesia \\ *Korespondesi email : izharrazi@gmail.com
}

\begin{abstract}
Abstrak
Tujuan penelitian ini untuk (1) untuk menjelaskan bagaimana tingkat partisipasi politik masyarakat dalam Pemilihan Kepala Daerah tahun 2018 di Kota BauBau (2) untuk mengidentifikasi faktor-faktor apa saja yang mempengaruhi partisipasi masyarakat Kota BauBau (3) untuk mengidentifikasi upaya-upaya apa saja yang dilakukan pihak KPUD Kota BauBau dalam meningkatkan partisipasi masyarakat. Data dikumpulkan dengan analisis dokumen, pengamatan, wawancara, dan dianalisis dengan tehnik deskriptif kualitatif dan Kuantitatif. Hasil dari penelitian ini adalah: (1) Tingkat partispasi masyarakat di Kota BauBau tergolong tinggi dikarenakan jika diakumulasikan sebesar 69,87\% \%. (2) Faktor - faktor yang mempengaruhi partisipasi politik masyarakat adalah (a) perangsang politik (b) Faktor karakteristik pribadi (c) faktor karakteristik sosial (d) keadaan politik. (3) Upaya yang dilakukan KPUD untuk meningkatkan partisipasi masyarakat adalah (a) sosialisasi pemilihan kepala daerah (b) membentuk Relawan Demokrasi (c) melaksanakan pendidikan pemilih (d) peran media massa.
\end{abstract}

Kata Kunci: Partisipasi Politik; PILKADA

\section{Political Participation Community of Regional Head Election Baubau City Year 2018}

\begin{abstract}
The objective of this research as follow: (1) to explain about how is people political participation in Regional Leader Election in 2018 at BauBau city; (2) to identify what's factor that influence people participation in BauBau city; (3) to identify what's efforts that been conducted by KPUD (Regional Election Committee) of BauBau city in improving people participation. Data collected with the analysis of documents, observation, interviews, and analyzed with a qualitative descriptive approach and quantitative. The results of this study are: (1) level of people participation in BauBau city included into high category because if it is accumulated, the result is 69,87\%. (2) factors that influence people political participation are (a) political stimulation, (b) personal characteristic factor, (c) social characteristic factor, (d) political situation. (3) the efforts that been conducted by KPUD to improve people participation as follow: (a) socialization of Regional Leader Election, b) creating Democracy Volunteer, (c) implementing election education, (d) the role of the media massa. Keywords: Political Power; Political Contestation; Local Actors
\end{abstract}




\section{Jurnal Ilmu Pemerintahan: Kajian Ilmu Pemerintahan dan Ilmu Politik, 4 (1), April}

2019- 30

\section{L.M. Azhar Sa'ban 1), Anwar Sadat 2), Nastia ${ }^{3)}$}

\section{PENDAHULUAN}

Pilkada langsung adalah wujud nyata dari pembentukan demokratisasi di daerah. Kepala Daerah dan wakil Kepala Daerah dipilih dalam satu pasangan calon yang dilaksanakan secara demokratis berdasarkan asas langsung, umum, bebas, rahasia, jujur dan adil. Pengajuan pasangan calon Kepala Daerah bisa dilakukan oleh partai politik atau gabungan partai politik yang memiliki kursi di DPRD dengan persyaratan tertentu dan/atau dari calon perseorangan dengan persyaratan tertentu pula. Dibutuhkan suatu pilihan yang tepat oleh rakyat terhadap pasangan Kepala Daerah sehingga dapat dihasilkan pasangan Kepala Daerah yang memiliki visi meningkatkan kesejahteraan rakyat daerah (Wahyu Widodo, 2015).

Berdasarkan pendapat yang dikemukakan di atas, maka pada hakikatnya pilkada merupakan sebuah peristiwa luar biasa yang dapat membuat perubahan berarti bagi daerah. Ini merupakan suatu cara dari kedaulatan rakyat yang menjadi esensi dari demokrasi. Oleh karena itu, esensi dari demokrasi yang melekat pada pilkada hendaknya disambut masyarakat secara sadar dan cerdas dalam menggunakan hak politiknya. Partisipasi, aktif, cermat, dan jeli hendaknya menjadi bentuk kesadaran politik yang harus dimiliki oleh masyarakat daerah dalam Pilkada ini.

Sebelum tahun 2005, kepala daerah dan wakil kepala daerah dipilih oleh Dewan Perwakilan Rakyat Daerah (DPRD). Sejak berlakunya UndangUndang Nomor 23 Tahun 2014 Tentang Pemerintah Daerah, Kepala Daerah dipilih secara langsung oleh rakyat melalui
Pemilihan Kepala Daerah dan Wakil Kepala Daerah atau disingkat Pilkada. Pemilihan Gubernur dan Wakil Gubernur, Bupati dan Wakil Bupati, serta Walikota dan Wakil Walikota yang selanjutnya disebut Pemilihan adalah pelaksanaan kedaulatan rakyat di wilayah provinsi dan kabupaten/kota untuk memilih Gubernur dan Wakil Gubernur, Bupati dan Wakil Bupati, serta Walikota dan Wakil Walikota secara langsung dan demokratis. Implementasi demokrasi di Indonesia salah satunya di wujudkan dalam penyelesaian Pemilihan Kepala Daerah secara langsung (Herry Febriadi, 2018).

Harapan besar mengenai implikasi Pilkada langsung ini, rakyat berharap dapat mengetahui dan memahami isi yang terkandung dalam undang-undang, sehingga lebih dapat meningkatkan pengetahuan serta wawasan politik atau pendidikan politik yang lebih dewasa terutama lebih memperhatikan aspek-aspek hubungan antar susunan pemerintahan dan antar pemerintah daerah. Implikasi lebih lanjut melalui pemahaman undangundang tersebut akan membuat rakyat menjadi paham politik, membangun tingkat kesadaran dalam berpolitik, serta masyarakat lebih kreatif dalam memilih calon kepala daerah yang mempunyai pemikiran yang ingin membangun daerahnya untuk maju dan sejahtera serta pelayanan publik yang lebih baik (Arther Muhaling, 2014).

Pelaksanaan Pemilihan Kepala Daerah secara langsung dan serentak di Indonesia diselenggarakan oleh Komisi Pemilihan Umum Daerah (KPUD) dan diawasi oleh Badan Pengawas Pemilu untuk tingkat provinsi dan Panitia Pengawas Pemilihan Kabupaten/Kota untuk 


\section{L.M. Azhar Sa'ban 1), Anwar Sadat 2), Nastia ${ }^{3)}$}

tingkat Kabupaten/Kota (Budi Evantri Sianturi \& Fifiana Wisnaeni, 2016).

Ajang pemilihan kepala daerah serentak telah berlangsung pada tanggal 27 Juni 2018, salah satu daerah yang mengikuti Pilkada serentak Tahun 2018 adalah Kota BauBau. Melalui Pemilihan Kepala Daerah, masyarakat lokal bisa menentukan nasibnya sendiri yang berkaitan dengan kepentingan mereka di daerah (Muhammad Asfar, 2006). Hal ini akan membawa perubahan pandangan masyarakat terhadap pemerintahan di daerah, karena calon yang akan memimpin dipilih langsung oleh rakyat. Proses ini membuktikan adanya sikap demokratis dan transparansi bagi rakyat yang akan memilih seorang pemimpin secara terbuka. Selain itu pemimpin yang dipilih nantinya akan memberikan kemampuan yang terbaik dalam mengelola dan mengatur kepemerintahannya. Harapan besar adalah pelayanan publik dan kesejahteraan akan lebih baik melalui pemilukada langsung ini.

Berdasarkan proses pendaftaran calon yang dilaksanakan sesuai dengan tahapan, Komisi Pemilihan Umum Kota BauBau menetapkan lima pasangan calon Walikota dan Wakil Walikota BauBau, nomor urut 1 pasangan calon $\mathrm{Hj}$. Roslina La Ode Yasin partai pengusung Hanura dan PKB, nomor urut 2 pasangan DR. H. A.S. Tamrin, M.H - La Ode Ahmad Monianse partai pengusung PAN, PDIP, Nasdem dan Golkar, nomor urut 3 pasangan Hj. Wa Ode Maasra Manarfa, S.Sos., M.Si - Ikhsan Ismail partai pengusung PBB dan Gerindra, nomor urut 4 pasangan $\mathrm{H}$. Yusran Fahim, SE - Drs. H. Ahmad, MM partai pengusung Demokrat, PPP dan PKS, nomor urut 5 pasangan Drs. H. Ibrahim Marsela, M.M - Ilyas, S.Sos calon perseorangan dengan jumlah dukungan sebanyak 11.642 KTP (KPUD Kota BauBau).

Masyarakat sebagai aktor utama dalam pemilihan ini dituntut agar lebih partisipatif dalam segala bentuk tahapan penyelenggaraan Pemilukada. Jumlah pemilih Kota Baubau dapat dilihat pada tabel berikut:

\section{Tabel 1. Rekapitulasi data pemilih}

\begin{tabular}{clcc} 
No & Kecamatan & $\begin{array}{c}\text { Jumlah } \\
\text { Pemilih }\end{array}$ & $\begin{array}{c}\text { Tingkat } \\
\text { Partisipasi } \\
\text { Pemilih }\end{array}$ \\
\hline $\mathbf{1}$ & Betoambari & 12.979 & 9.325 \\
$\mathbf{2}$ & Batupoaro & 20.495 & 14.248 \\
$\mathbf{3}$ & Murhum & 13.656 & 10.462 \\
$\mathbf{4}$ & Wolio & 30.722 & 20.258 \\
$\mathbf{5}$ & Bungi & 5.206 & 4.540 \\
$\mathbf{6}$ & Sorawolio & 5.220 & 3.829 \\
$\mathbf{7}$ & Kokalukuna & 13.308 & 9.997 \\
$\mathbf{8}$ & Lea-Lea & 5.368 & 4.162 \\
& Jumlah & 106.954 & 76.821 \\
\hline
\end{tabular}

Sumber: KPUD Kota BauBau Tahun 2018

Salah satu faktor pendukung Pemilukada adalah tingkat partispasi masyarakat, jumlah partisipasi yang banyak akan menunjukkan kesadaran masyarakat tentang pentingnya Pemilukada. Meskipun jika pada akhirnya tingkat partisipasi masyarakat rendah tidak dapat membatalkan hasil Pemilukada, namun hal ini dapat menunjukkan kesadaran politik masyarakat dalam memposisikan dirinya sebagai unsur sentral suatu daerah.

Partisipasi yang lemah berakibat pada sebuah realitas politik yang kini menggejala di permukaan dan terkait dengan era otonomi daerah yaitu terjadinya kesenjangan politik antara masyarakat sipil dengan lembaga 


\section{Jurnal Ilmu Pemerintahan: Kajian Ilmu Pemerintahan dan Ilmu Politik, 4 (1), April 2019- 32}

\section{L.M. Azhar Sa'ban 1), Anwar Sadat 2), Nastia ${ }^{3)}$}

kekuasaan lokal, dimana faktor pelaksana kekuasaan lokal sering melakukan langkah pengambilan dan pelaksanaan kebijakan politik yang tidak selaras dengan aspirasi kolektif masyarakat sipil.

Dari tabel diatas menjelaskan bahwa masih belum maksimal partisipasi politik masyarakat dalam kegiatan Pemilihan Kepala Daerah di Kota BauBau, dapat dilihat dari masih banyaknya masyarakat yang tidak menggunakan hak pilihnya, dengan berbagai alasan dan penyebab yang berbeda-beda. Berdasarkan uraian tersebut, penulis tertarik untuk melakukan penelitian dengan jidul Partisipasi Politik Masyarakat dalam Pemilihan Kepala Daerah Kota BauBau Tahun 2018.

\section{Partisipasi Politik}

Partisipasi politik masyarakat merupakan bentuk perwujudan negara demokrasi, dimana masyarakat dilibatkan langsung dalam Pemilihan Umum. Dalam hal ini, warga negara berperan penting dalam menseleksi pejabat-pejabat negara yang nantinya akan mengatur pemerintahan maupun tindakan-tindakan yang akan mereka ambil nantinya (Suryadi, 2007).

partisipasi politik adalah hasrat seorang individu untuk mempunyai peran dalam kehidupan politik melalui keterlibatan administratif untuk menggunakan hak bersuara, melibatkan dirinya diberbagai organisasi, mendiskusikan berbagai persoalan politik dengan pihak lain, ikut serta melakukan berbagai aksi dan gerakan, bergabung dengan partai-partai atau organisasiorganisasi independent, ikut serta dalam kampanye penyadaran, memberikan penyadaran, memberikan pelayanan terhadap lingkungan dengan kemampuanya sendiri (Arther Muhaling, 2014).

Partisipasi politik dapat bermanfaat untuk: (1) memberikan dukungan kepada penguasa dan pemerintah dalam bentuk pengiriman wakil atau pendukung, pembuatan pernyataan yang isinya memberikan dukungan terhadap pemerintah, dan pemilihan calon yang diusulkan oleh organisasi politik; (2) menunjukan kelemahan dan kekurangan pemerintah dengan harapan agar pemerintah meninjau kembali, memperbaiki, atau mengubah kelemahan tersebut; (3) partisipasi sebagai tantangan terhadap penguasa supaya terjadi perubahan struktural dalam pemerintahan dan dalam sistem politik (Syamsudin Haris, 2014).

Bahwa semua warga negara memiliki peluang dan kesempatan yang sama dalam mengevaluasi dan menentukan pemimpinnya, sehingga partisipasi politik, dalam hal ini keikutsertaan warga negara dalam PILKADA, menjadi penting. Pada sisi yang sama, pemahaman yang baik terhadap peran-peran strategis warga negara juga akan mendorong kualitas demokrasi (Liando dkk, 2015).

\section{Pemilihan Kepala Daerah}

Manakala Pemilihan Kepala Daerah (PILKADA) memang diakui secara global, sebagai sebuah arena untuk membentuk demokrasi perwakilan serta menggelar pergantian pemerintahan secara berkala (Rahmatunnisa, 2017).

Tujuan utama PILKADA adalah rakyat daerah bisa menentukan sendiri orang tertentu yang dianggap atau dinilai mampu membawa kebaikan bagi seluruh rakyat di daerah tersebut. Pemilihan Kepala Daerah secara langsung dinilai 


\section{L.M. Azhar Sa'ban 1), Anwar Sadat 2), Nastia ${ }^{3)}$}

sebagai sarana dan cermin atas hak dasar kedaulatan rakyat dengan memberikan kewenangan yang utuh dalam melaksanakan serta menentukan pimpinan daerah untuk mewujudkan demokrasi tingkat lokal. Menurut teori demokrasi minimalis dari Schumpeterian, PILKADA merupakan sebuah arena yang mewadahi kompetisi atau kontestasi antara aktor politik untuk meraih kekuasaan; partisipasi politik rakyat untuk menentukan pilihan; serta liberalisasi hak-hak sipil dan politik warga negara ( $c f$ Dahl, 2001; Harahap, 2010; Mitchell, 2015; dan Liando, 2016).

Demokrasi juga menggariskan bahwa PILKADA adalah kesempatan bagi partai oposisi dan rakyat untuk menjalankan mekanisme check and balances terhadap partai yang berkuasa atau ruling party (Asrinaldi, 2013). Meski banyak kalangan menilai konsepsi demokrasi seperti ini cenderung minimalis, namun praktek demokrasi yang minimalis tersebut telah membentuk sebuah sistem penentuan/ pengisian jabatan-jabatan publik di semua negara demokratis. Artinya bahwa PILKADA telah terlembaga secara institusional dan menjadi mekanisme universal dalam sistem politik di negara-negara demokratis (Liando, 2016).

$$
\text { Dalam konteks PILKADA, }
$$

mekanisme pemilihan dikatakan demokratis apabila memenuhi beberapa parameter, yakni: adanya pemilihan kepala daerah yang jujur dan adil; rotasi kekuasaan yang damai; rekrutmen secara terbuka; dan akuntabilitas publik (Dahl, 2001; dan Nopyandri, 2012). Merujuk pada pandangan tersebut, semakin jelas bahwa semangat demokrasi menuntut ruang partisipasi yang luas dan telah mengkonstruksi sistem demokrasi kita pada demokrasi langsung, dimana rakyat secara langsung berpartisipasi untuk menentukan pilihan politiknya tanpa diwakilkan.

\section{METODE}

Kajian ini merupakan penelitian kepustakaan (library research), dengan menggunakan pendekatan deskriptif dan metode kualitatif (Creswell, 2010). Teknik pengumpulan datanya dilakukan dengan cara memanfaatkan kepustakaan dan penelusuran data online, serta wawancara mendalam pada masyarakat dan tokoh masyarakat di Kota BauBau, yang kompeten menjawab masalah politik (Bushman \& Wells, 2001).

Data penelitian kemudian dianalisis dengan teknik analisis data kualitatif, yang tahapannya terdiri dari reduksi data atau data reduction; penyajian data atau data display; dan penarikan kesimpulan atau conclusion drawing (Bloor, 1997).

\section{HASIL DAN PEMBAHASAN}

Tingkat Partisipasi Politik Mayarakat dalam Pelaksanaan Pemilihan Kepala Daerah Kota Baubau Tahun 2018

Pada tanggal 27 Juni 2018 ajang pemilihan kepala daerah serentak telah berlangsung di Kota Baubau. Masyarakat Kota BauBau mengadakan Pemilihan Kepala Daerah, dimana ditemukan presentase tingkat partisipasi pemilih mencapai $69,87 \%$ dan sisanya $30,13 \%$ adalah masyarakat yang tidak menggunakan hak pilihnya.

Dari persentase perolehan suara diatas dapat diketahui bahwa tingkat partisipasi masyarakat Kota BauBau pada saat Pemilihan Kepala Daerah tahun 2018 tergolong cukup tinggi. 


\section{Jurnal Ilmu Pemerintahan: Kajian Ilmu Pemerintahan dan Ilmu Politik, 4 (1), April}

2019- 34

\section{L.M. Azhar Sa'ban 1), Anwar Sadat 2), Nastia ${ }^{3)}$}

Dalam meraih demokrasi, partisipasi politik merupakan unsur penting yang harus ada dalam setiap pemilihan Kepala Daerah. Kebebasan dalam mengeluarkan pendapat dan memilih suatu calon mutlak harus ada didalam suatu Negara yang bercirikan demokrasi didalamnya, tak terkecuali di Indonesia. Adanya kebebasan rakyat dalam menjalankan partisipasi politik menjadi tolak ukur untuk melihat eksistensi demokrasi dalam suatu Negara.

\section{Faktor-Faktor yang Mempengaruhi Partisipasi Politik Masyarakat}

Dari hasil temuan penelitian faktorfaktor yang mempengaruhi partisipasi politik masyarakat pada Pemilihan Kepala Daerah di Kota BauBau pada tahun 2018 adalah (1). Faktor Perangsang Politik (2). Faktor Karakteristik Pribadi (3). Faktor Karakteristik Sosial (4). Faktor Keadaan Politik. Pelaksanaan Partisipasi politik masyarakat tentu saja tidak berlangsung tanpa adanya faktor - faktor pendukung, tentu saja banyak hal yang sangat mempengaruhi pelaksanaan partisipasi politik masyarakat.

\section{Upaya-upaya KPUD dalam Meningkatkan Partisipasi Politik Masyarakat}

Dari temuan penelitian, upaya KPUD untuk meningkatkan partisipasi dalam Pemilihan Kepala Daerah Kota BauBau yang berlangsung pada tahun 2018. Penjelasannya sebagai berikut:

1) Sosialisasi Pemilihan Kepala Daerah

Hal yang perlu dilakukan adalah memaksimalkan proses sosialisasi tentang pentingnya Pemilu dalam sebuah Negara yang demokratis, bukan hanya sosialisasi teknis penyelenggaraan Pemilu. Meskipun dalam ketentuan undang-undang menyatakan bahwa sosialisasi dilakukan terkait dengan teknis penyelenggaraan Pemilu, namun sosialisasi segala hal yang melatarbelakangi penyelenggaraan Pemilu perlu untuk dilakukan.

2) Membentuk Relawan Demokrasi

Program relawan demokrasi adalah gerakan sosial yang dimaksudkan untuk meningkatkan partisipasi dan kualitas pemilih dalam menggunakan hak pilih. Program ini melibatkan peran serta masyarakat yang seluas-luasnya dimana mereka ditempatkan sebagai pelopor (pioneer) demokrasi bagi komunitasnya. Relawan demokrasi menjadi mitra KPU dalam menjalankan agenda sosialisasi dan pendidikan pemilih berbasis kabupaten/kota. Bentuk peran serta masyarakat ini diharapkan mampu mendorong tumbuhnya kesadaran tinggi serta tanggung jawab penuh masyarakat untuk menggunakan haknya dalam pemilu secara optimal.

3) Memberikan pendidikan bagi pemilih

Pendidikan bagi pemilih perlu mendapatkan fokus yang jelas. Ini terkait dengan proses segmentasi pendidikan pemilih. Pemilih pemula merupakan segmentasi penting dalam upaya melakukan pendidikan bagi pemilih dan tentunya pendidikan bagi pemilih pemula ini tidak hanya dilakukan ketika masuk usia pilih.

Namun lebih dari itu, pendidikan bagi pemula seyogyanya dilakukan sedini mungkin, sehingga pemahaman tersebut terbangun dan ketika sudah mencapai usia pemilih, para pemilih pemula sudah siap menggunakan hak pilihnya secara cerdas.

\section{4) Peran Media Massa}

Menciptakan masyarakat untuk mengikuti perkembangan proses Pemilu 


\section{Jurnal Ilmu Pemerintahan: Kajian Ilmu Pemerintahan dan Ilmu Politik, 4 (1), April 2019- 35}

\section{L.M. Azhar Sa'ban 1), Anwar Sadat 2), Nastia ${ }^{3)}$}

melalui media massa, ini telah menjadi salah satu bentuk sosialisasi kepada masyarakat, sehinnga masyarakat tahu dengan pasti tentang proses Pilkada.

Terkait dengan peningkatan kinerja penyelenggara Pemilu, bukan hanya terkait dengan kinerja teknis penyelenggaraan, namun juga dalam hal penumbuhan kesadaran tentang pentingnya partisipasi masayarakat dalam penyelenggaraan Pemilu, sehingga masyarakat bisa memahami partisipasi apa saja yang dapat dilakukan dan apa output dari partisipasi tersebut. Selain upaya sosialisasi pihak KPUD juga berusaha mempercepat percetakan surat suara agar bisa memenuhi deadline sebelum pilkada dimulai.

\section{SIMPULAN}

Berdasarkan hasil penelitian, dan pembahasan penelitian yaitu yang pertama masyarakat Kota BauBau telah berpartisipasi dalam Pemilihan Kepala Daerah pada tanggal 27 Juni 2018 dalam rangka memilih Walikota dan Wakil Walikota dan berdasarkan data-data yang ada jumlah pemilih di Kota BauBau adalah 106.947, dapat dilihat tingkat partisipasi masyarakat Kota BauBau cukup tinggi presentase jumlah pemilih yaitu $69,87 \%$ (76.821) dan sisanya tindak menggunakan hak pilih 30,13\% (30.133). Temuan penelitian kedua yaitu dibalik presentase tingkat partisipasi masyarakat yang tinggi tentu saja ada faktor-faktor yang mempengaruhi tingkat partisipasi politik masyarakat Kota BauBau.

Faktor - faktor yang mempengaruhi yaitu adanya (1) Rangsangan politik yang berasal dari media massa, karena pada zaman modern seperti ini media massa merupakan sarana informasi yang sangat mudah sekali diakses oleh masyarakat, dan dari ini masyarakat dapat mengetahui informasi dan mengenal sapa saja calon Wali Kota dan Wakil Walikota. (2) Faktor karakteristik pribadi, pendidikan agama yang diberikan sejak dini besar sekali pengaruhnya terhadap masyarakat untuk ikut berpartisipasi politik karena masyarakat Kota BauBau sangat kental dengan pendidikan agamanya maka masyarakat lebih condong untuk memilih pasangan Wali Kota dan Wakil Walikota yang dapat menjaga amanah dan dapat bertanggung jawab untuk memipin Kota BauBau. (3) Keadaan politik apabila suatu daerah keadaan politiknya tidak mengalami tekanan dari dalam maupun luar, masyarakat akan lebih merasa bebas dan akan mempunyai keinginan dan kesadaran untuk nmengikuti partisipasi politik.

Hasil penelitian ketiga yaitu, di balik suksesnya Pemilihan Kepala Daerah ada KPUD yang merupakan badan penyelenggara Pemilihan Kepala Daerah. Selain itu KPUD juga mempunyai tugas untuk meningkatkan partisipasi masyarakat dengan cara gencar melakukan sosialisasi Pemilukada baik kepada masyarakat yang didalamnya ada pemilih muda. Dimana pemilih muda membutuhkan pendidikan politik agar mampu menjadi pemilih cerdas di kemudian hari.

\section{Rekomendasi}

Berdasarkan kesimpulan diatas, maka saran penulis adalah sebagai berikut: (1) Perkembangan zaman yang sangat cepat ini media massa merupakan salah satu media informasi yang sangat mudah diterima oleh kalangan masyarakat. Siapapun bisa mengakses informasi apapun tidak terkecuali tentang 


\section{Jurnal Ilmu Pemerintahan: Kajian Ilmu Pemerintahan dan Ilmu Politik, 4 (1), April 2019- 36}

\section{L.M. Azhar Sa'ban 1), Anwar Sadat 2), Nastia ${ }^{3)}$}

masalah politik. Pemilu dikatakan dapat berhasil apabila adanya kesadaran masyarakat dan informasi pemilih. Artinya bahwa seorang pemilih wajib mengetahui bagaimana proses, tata cara, dan tahap-tahap Pemilihan Kepala Daerah. Oleh karena itu media massa harus menyajikan tayangan yang mendidik agar para pemilih dapat menentukan pilihannya benar - benar dari hati nurani. (2) Masyarakat diharapkan untuk lebih sering mengikuti informasi baik dari media massa atau mengikuti sosialisasi yang diadakan oleh KPUD dan dibantu juga oleh Relawan Demokrasi, agar tumbuh perasaan sadar akan pentingnya mengikuti Pemilihan Kepala Daerah. (3) Pihak KPUD diharapakan untuk lebih gencar lagi melakukan sosialisasi pada masyarakat terutama pemilih pemula. Hal ini dilakukan agar berkurangnya angka golput yang sering dilakukan oleh masyarakat dan pemilih pemula. (5) Perlu adanya kerjasama antara lembaga penyelenggara Pemilihan Kepala Daerah yaitu KPUD Kota BauBau, partai politik, serta organisasi kemasyarakatan untuk meningkatkan pendidikan kepada masyarakat terkait pemahaman pemilu.

\section{Ucapan Terima Kasih}

Ucapan terima kasih sebesar-besarnya kepada Universitas Muhammadiyah Buton yang telah mendanai skema penelitian internal tahun 2018 dengan tujuan untuk meningkat publikasi serta penelitian dosen. Terima kasih juga kepala Lembaga Penelitian, dan Pengabdian kepada Masyarakat (LPPM) UMB yang telah bekerja keras sehingga Penelitian Internal bisa dilaksanakan sampai selesai. Para dosen Prodi Ilmu Pemerintahan yang telah memberikan fasilitas serta jalan selama penelitian berlangsung.

\section{DAFTAR PUSTAKA}

Arther Muhaling, (2014). Partisipasi Politik Masyarakat Dalam Pemilukada Di Kecamatan Siau Barat Selatan Kabupaten Sitaro. Jurnal Politico. Volume 1. No. 5. Retrieved from Https://Ejournal.Unsrat.Ac.Id/Index.Ph p/Politico/Article/View/7100

Asfar, Muhammad. (2006). Mendesain Managemen Pilkada, Surabaya: Pustaka Eureke.

Asrinaldi, A. (2013). "Koalisi Model Parlementer dan Dampaknya pada Penguatan Kelembagaan Sistem Presidensial di Indonesia" dalam Jurnal Penelitian Politik, Vol.10, No.2 [Desember]. Retrieved from http://ejournal. politik.lipi.go.id/index.php/jpp/article/ viewFile/435/248 [diakses di Wamena, Papua, Indonesia: 10 November 2017].

Budi Evantri Sianturi \& Fifiana Wisnaeni, (2016). Penguatan Kelembagaan Panwas Pemilihan Dalam Menyelesaikan Pelanggaran Pemilihan Kepala Daerah (Studi Kasus Penyelesaian Pelanggaran Administrasi, Pidana, Dan Kode Etik Pemilihan Walikota Dan Wakil Walikota Semarang Tahun 2015). Jurnal Law Reform Volume 12, No. 2. Retrieved from https://ejournal.undip.ac.id/index.php /lawreform/article/viewFile/15873/1 1844

Bushman, B. \& G. Wells. (2001). "Narrative Impressions of Literature: The Availability Bias and the Corrective Properties of Meta-Analytic Approaches" in Personality and Social Psychology Bulletin, Volume 27, pp.1123-1130. Retrieved from https://www.researchgate.net/publica tion/237251148_Narrative_Impression s_of_Literature_The_Availability_Bias_a 


\section{Jurnal Ilmu Pemerintahan: Kajian Ilmu Pemerintahan dan Ilmu Politik, 4 (1), April 2019- 37}

\section{L.M. Azhar Sa'ban 1), Anwar Sadat 2), Nastia ${ }^{3)}$}

nd_the_Corrective_Properties_of_MetaAnalytic_Approaches

Bloor, M. (1997). Techniques of Validation in Qualitative Research: A Critical Commentary. London: Sage.

Creswell, John W. (2010). Research Design: Pendekatan Kualitatif, Kuantitaif, dan Mixed. Yogyakarta: Pustaka Pelajar, Terjemahan.

Dahl, Robert A. (2001). Perihal Demokrasi: Menjelajahi Teori dan Praktek Demokrasi secara Singkat. Jakarta: Yayasan Obor Indonesia, terjemahan A. Rahman Zainuddin.

Harahap, Husnul Isa. (2010). "Robert A. Dahl dan Studi tentang Fenomena Demokrasi di India" dalam Jurnal POLITEIA, Vol.2, No.1 [Januari]. Retrieved from https://jurnal.usu.ac.id/index.php/poli teia/article/view/16122/6973

Haris, Syamsudin, (2014). Partai, Pemilu, dan Parlemen di Era Reformasi. Jakarta: Yayasan Pustaka Obor Indonesia.

Herry Febriadi, (2018). Implementasi Undang-Undang No 7 Tahun 2017 Terhadap Kedudukan Dan Kinerja Panitia Pengawas Pemilu Kabupaten Hulu Sungai Utara. Al'Adl, Volume X, No.1. Retrieved from https://ojs.uniskabjm.ac.id/index.php/ aldli/article/download/1152/972

KPUD Kota BauBau, (2018). Visi Misi Program, dan Profil Calon Walikota dan Wakil Walikota BauBau Periode 2018-2023. Cetakan 1, Kendari: Komunika.

Liando, Daud Ferry \& Winsi Kuhu. (2015). "Partisipasi Politik Masyarakat Terkait Pemberian Suara pada Pemilihan Anggota Legislatif dan Pemilihan Presiden dan Calon Wakil Presiden di Kabupaten Minahasa Tahun 2014". Laporan Hasil Penelitian. Minahasa: KPU (Komisi Pemilihan Umum) Kabupaten Minahasa. Retrieved from
https://kpu.go.id/koleksigambar/Parti sipasi_politik_masyarakat_Minahasa.pd $\mathrm{f}$

Liando, Daud M. (2016). "Pemilu dan Partisipasi Politik Masyarakat: Studi pada Pemilihan Anggota Legislatif dan Pemilihan Presiden dan Calon Wakil Presiden di Kabupaten Minahasa Tahun 2014" dalam Jurnal LPPM Bidang EkoSosBudKum, Vol.3, No.2 [Oktober]. Retrieved from

https://ejournal.unsrat.ac.id/index.php /lppmekososbudkum/article/viewFile/ 17190/16738

Mitchell, Bruce. (2015). "Participatory Partnerships: Engaging and Empowering to Enhance Environmental Management and Qualityof Life" in Social Indicators Research, Volume 71, pp.123-144. Retrieved from https://www.researchgate.net/publica tion/225977876_Participatory_Partner ships_Engaging_and_Empowering_to_E nhance_Environmental_Management_a nd_Quality_of_Life

Nopyandri. (2012). "Pemilihan Kepala Daerah yang Demokratis dalam Perspektif UUD 1945" dalam Jurnal Ilmu Hukum, Vol.2, No.2. Retrieved from https://media.neliti.com/media/public ations/9117-ID-pemilihan-kepaladaerah-yang-demokratis-dalamperspektif-uud-1945.pdf

Rahmatunnisa, Mudiyati. (2017). "Mengapa Integritas Pemilu Penting?" dalam Jurnal BAWASLU, Vol.3, No.1, hlm.1-11. Retrieved from https://bawaslu.go.id/sites/default/fil es/publikasi/01\%20JURNAL\%20BAW ASLU.pdf

Suryadi, Budi, (2007). Sosiologi Politik: Sejarah, Definisi dan Perkembangan Konsep. Yogyakarta: IRCiSoD

Undang Nomor 23 Tahun 2014 Tentang Pemerintah Daerah. Retrieved from 
Jurnal Ilmu Pemerintahan: Kajian Ilmu Pemerintahan dan Ilmu Politik, 4 (1), April 2019- 38

\section{L.M. Azhar Sa'ban 1), Anwar Sadat 2), Nastia ${ }^{3)}$}

http://dispenda-kaltimprov.org/wpcontent/uploads/2013/04/UndangUndang-Republik-Indonesia-Nomor23-Tahun-2014-Tentang-

Pemerintahan-Daerah.pdf

Wahyu Widodo, (2015). Pelaksanaan Pilkada Berdasarkan Asas Demokrasi Dan NilaiNilai Pancasila. Jurnal Ilmiah CIVIS, Volume V, No 1. Retrieved from http://journal.upgris.ac.id/index.php/c ivis/article/download/629/579

\section{PROFIL SINGKAT}

\section{L.M. Azhar Sa'ban. SH.,M.I.P}

Lahir di Ngangana Umala tanggal $21 \mathrm{Mei}$ 1988. Lulusan Srata Satu (S1) pada tahun 2011 dengan jurusan Ilmu Hukum di Universitas Dayanu Ikhsanuddin. Kemudian melanjutkan Pascasarjana Magister Ilmu Pemerintahan (S2) di Universitas Muhammadiyah Yokyakarta dan menyelesaikan pada tahun 2014. Karir Akademisi sejak tahun 2017 di Universitas Muhammadiyah Buton dan aktif sebagai dosen di Prodi Ilmu Pemerintahan. Penulis dapat dihubungi melalui e-mail: izharsky@yahoo.co.id.

\section{Anwar Sadat. S.Sos., M.I.P}

Lahir di Ollo tanggal 19 September 1975. Lulusan Srata Satu (S1) pada tahun 1999 dengan jurusan Ilmu Komunikasi di Universitas Sulawesi Tenggara. Kemudian melanjutkan Pascasarjana Magister Ilmu Pemerintahan (S2) Universitas Muhammadiyah Yokyakarta dan menyelesaikan pada tahun 2014. Karir Akademisi sejak tahun 2008 di Universitas Muhammadiyah Buton dan aktif sebagai dosen di Prodi Ilmu Pemerintahan. Penulis dapat dihubungi melalui e-mail: nuansa9@gmail.com.

\section{NASTIA, S.IP.,M.I.P}

Kelahiran Lipu Kadatua Buton Selatan, 30 Desember 1983. Lulusan Srata Satu (S1) pada tahun 2005 dengan jurusan Ilmu Pemerintahan di Universitas Sam Ratulangi Manado Sulawesi Utara. Kemudian melanjutkan Pascasarjana Ilmu Pemerintahan (S2) di Universitas Muhammadiyah Yogyakarta dan menyelesaikan pada tahun 2014. Karir Akademisi sejak tahun 2009 di Universitas Muhammadiyah Buton dan aktif sebagai dosen di Prodi Ilmu Pemerintahan. Penulis dapat dihubungi melalui e-mail: tianas21@yahoo.co.id 